Working Paper/Document de travail 2012-26

\title{
Natural Monopoly and Distorted Competition: Evidence from Unbundling Fiber-Optic Networks
}

by Naoaki Minamihashi 
Bank of Canada Working Paper 2012-26

August 2012

\title{
Natural Monopoly and Distorted Competition: Evidence from Unbundling Fiber-Optic Networks
}

\author{
by \\ Naoaki Minamihashi \\ Financial Markets Department \\ Bank of Canada \\ Ottawa, Ontario, Canada K1A 0G9 \\ nminamihashi@bankofcanada.ca
}

Bank of Canada working papers are theoretical or empirical works-in-progress on subjects in economics and finance. The views expressed in this paper are those of the author. No responsibility for them should be attributed to the Bank of Canada. 


\section{Acknowledgements}

This paper has benefitted from continuous suggestions and the overall guidance of Marc Rysman. The industrial research background relies heavily on the deep knowledge of Ingo Vogelsang. I am indebted to Matthew Chesnes, Scott Hendry, Takanori Ida, Jordi Jaumandreu, Joshua Lustig, Keizo Mizuno, Hector Perez Saiz, David Prentice, Yuya Takahashi, Ben Tomlin, Masatsugu Tsuji and Jonathan Witmer for discussions that generated great improvements. I also thank M. Hansen, C. Ho, T. Kuroda, M. Sunada, E. Yilmaz and participants at Boston U., CEA, EARIE, ESNASM, IIOC, ITS, JEA, JFTC, KGIO, Osaka U., SAEe and TPRC. I acknowledge the help Hiroshi Ohashi, MIC and NTT East for data usage, and Masaru Fujino (MIC) and Hirofumi Suto (NTT) for Japanese regulation knowledge. This paper was awarded 1st prize in the TPRC student paper competition and the Moriguchi Prize from the ISER at Osaka University. I acknowledge the Talent Strategy Grant from the Bank of Canada. The author takes full responsibility for any remaining errors. This paper was previously circulated as "Prevention of Competition by Competition Law." 


\begin{abstract}
Can regulation solve problems arising from a natural monopoly? This paper analyzes whether "unbundling," referring to regulations that enforce sharing of natural monopolistic infrastructure, prevents entrants from building new infrastructure. It models and estimates a dynamic entry game to evaluate the effects of regulation, using a dataset for construction of fiber-optic networks in Japan. The counterfactual exercise shows that forced unbundling regulation leads to a $24 \%$ decrease in the incidence of new infrastructure builders. This suggests, therefore, that when a new technology is being diffused, regulation to remove a natural monopoly conversely involves risks that regulated monopolists' shares will increase.
\end{abstract}

JEL classification: K23, L43, L96

Bank classification: Market structure and pricing; Productivity

\title{
Résumé
}

La réglementation peut-elle résoudre les problèmes associés à un monopole naturel? L'auteur étudie si le «dégroupement", dont l’imposition oblige les entreprises qui exercent un monopole naturel à partager leur infrastructure, empêche la construction de nouvelles infrastructures par des firmes faisant leur entrée sur le marché. Afin d'évaluer les effets de la réglementation, l'auteur modélise et estime un jeu dynamique d'entrée en utilisant un ensemble de données relatives à la construction de réseaux à fibres optiques au Japon. Les résultats de la simulation contrefactuelle indiquent que le recours forcé au dégroupement fait diminuer de $24 \%$ le nombre de nouveaux constructeurs d'infrastructure. L'étude donne donc à penser qu'en période de diffusion d'une nouvelle technologie, chercher à supprimer un monopole naturel par la voie de la réglementation risque plutôt d’accroître la part du marché du monopoleur réglementé.

Classification JEL : K23, L43, L96

Classification de la Banque : Structure de marché et fixation des prix; Productivité 
Should we use regulation to encourage competition? Historically, government authorities have sought to foster competition by regulating the bundling behaviours of firms. In general, firms that have natural monopolistic infrastructures often offer their own services exclusively by bundling. For example, electric companies traditionally bundle the generation of electricity with the distribution of electricity via a monopolistic power grid system. ${ }^{1}$ More recently, Microsoft has bundled software with its operating system. Apple also bundles music players and cell phones with its digital music download system. If incumbent firms bundle these key infrastructures and offer their services exclusively, new entrants must themselves provide this type of a bottleneck infrastructure in order to enter the markets. However, the costs of providing this infrastructure can be prohibitive, and, as a result, firms do not enter the market. This is the main argument for the regulation of monopolistic infrastructures.

Competition in the telecommunication industry has historically been highly regulated. Governments around the world have adopted "unbundling" regulations to accelerate competition among carriers. This regulation requires that telephone companies that have a monopoly on local lines share them with other companies at a regulated price. ${ }^{2}$ Local telephone lines are characterized as a "natural monopoly"; it is not feasible for new entrants to build and maintain the lines due to huge sunk costs. Absent regulation, there would be little competition in the industry and the incumbent could charge monopolistic prices. Hence, governments regulate carriers with this infrastructure in place to allow other firms to use their equipment, so that firms with no infrastructure can more easily enter the markets, ensuring that consumers have access to a wide variety of high quality services at a competitive price. ${ }^{3}$

Policymakers in telecommunications, however, are confronted with a new problem, namely promoting the building of fiber-optic networks called fiber to the home (FTTH). These new fiberoptic lines can transfer large amounts of data with faster transfer rates, enabling services such as high speed internet, HDTV programs and cloud computing, and will replace traditional telephone lines and cable TV lines. However, unbundling regulations decrease the incentive for fiber-optic network builders to invest in this latest technology; as a result, few firms build home fiber-optic networks. They forgo opportunities for monopolistic profits since they have to lend the fiber lines at a low cost. Thus in 2003, the United States' Federal Communications Commission (FCC) amended the law and removed unbundling regulations on fiber-optic premises in order to accel-

\footnotetext{
${ }^{1}$ The gas, water, postal and railroad industries have similar characteristics.

2"Unbundling" here means a regulation to open a natural monopolistic infrastructure. This word comes from prohibiting the bundling of an natural monopolistic infrastructure with its usage.

${ }^{3}$ Industries that have similar natural monopolistic characteristics, such as the electric, gas, and railroad industries, also have unbundling regulations. Indeed, industries without such regulations can run into trouble with consumers and governments alike: recently, Microsoft and Apple have also been criticized for their monopolistic stance with respect to their products Windows and iTunes, which prevents competition.
} 
erate infrastructure competition among carriers and promote investments in fiber-optic networks, even though many companies without facilities harshly objected. ${ }^{4}$ A change in unbundling regulations could thus have an immense effect on investment in the information and telecommunications industry, the penetration of fiber-optic networks, consumer welfare, and, ultimately, a country's productivity. Therefore, the regulation of fiber-optic networks is an important concern of policymakers in the world today.

However, few studies have examined the importance of unbundling regulations. The previous literature focuses mainly on the effects of unbundling on service markets, such as the market for the use of telephone lines. Using U.S. data, Greenstein and Mazzeo (2006) find that unbundling widens the variety of entrants. Similarly, Economides, Seim and Viard (2008) find that competition in service markets induced by unbundling fosters lower-prices and higher-quality services. Grajek and Roller (2012) find that access regulation decrease both total industry and individual carrier investment using EU country-level data. Despite this literature, the effects of unbundling on infrastructure competition itself have not been thoroughly considered, even though it is one of the key elements for this type of regulations. This is because the construction of new infrastructure under unbundling regulation is uncommon, and also because micro-level data on regulation are not readily available. For example, in the telecommunication industry, metal networks were built more than 50 years ago; the new fiber networks that are being formed will be the first since the 1960s. We use this event for identifying the effect of unbundling on infrastructure market structure. In addition, this paper models dynamic strategic behaviours between infrastructure builders and users, then quantifies the effects of regulation by counterfactual simulation.

This paper uses fiber-construction data from Japan for three reasons. First, Japan has experienced a rapid increase in the number of FTTH networks, while other countries have not yet installed home fiber-optic networks. ${ }^{5}$ Second, Japan continued to regulate the unbundling of fiberoptic lines during the construction of these networks, while other countries abandoned regulation.

\footnotetext{
${ }^{4}$ This deregulation of fiber-optic networks has been continually criticized by firms that use the unbundling system and has created a controversy involving regulatory authorities. For example, in December 2009, Cbeyond,Inc, supported by the Small Business Administration (SBA), filed a petition with the FCC to reverse the deregulation on fiber-optic lines in the U.S. In response to this, the Telecommunications Industry Association (TIA) and the Fiber-tothe-Home (FTTH) Council in January 2010 jointly filed with the FCC not to reverse the deregulation. Similar disputes exist in Asia and Europe. For example, in Japan, SoftBank Corp., a firm using the unbundled facilities of another, filed a lawsuit to ease the condition of fiber-unbundling in December 2011. In Australia, the largest telecom company, Telstra, declared that it will not build fiber-optic networks if the unbundling regulation will be enforced on fiber-optic lines.

${ }^{5}$ The reason Japan experienced rapid diffusion is still an open question. It may come from its high population density or cultural background of preference for high technology. Another reason may be the low installation cost of fiber-optic lines. In Japan, most telephone/power lines are built using telephone poles, whereas other developed countries in North America or Europe bury telephone lines underground because they value the scenery. It is more costly to bury fiber-optic lines. Some economists claim that unbundling regulations promote diffusion as in Berkman Report (2009), but there are also critiques of this view.
} 
Table 1 shows the international comparisons for the diffusion and regulation of fiber-optic networks. Finally, in Japan, authorities and regulated firms also provide micro-level data, which are not available in other countries.

Thus, by assessing the Japanese data, we can throw light on the general question of how unbundling affects new infrastructure construction and assess the policy changes in the U.S. and other countries. From 2005 to 2009, the Japanese government continued to enforce unbundling regulations on new fiber-optic lines during an important period of fiber-optic network construction. In the process, cable television and electric companies, competitors of the regulated firms, reduced or stopped building fiber-optic lines. They claimed that the unbundling regulations on incumbents decreased other firms' incentives to build their own lines. Even though they were not regulated to lend their lines to other companies, ${ }^{6}$ these firms were concerned because they would have to reduce their price to compete with regulated companies and firms using the unbundled lines. Compared with this, regulated companies increased their shares because they must lend unbundled lines to all other firms wanting to borrow them. ${ }^{7}$ As a result, in Japan, regulated firms have dominated the infrastructure markets with the increase of unbundling usage, and regulators failed to encourage competition in the building of fiber-optic networks. ${ }^{8}$ The regulation to remove the "natural monopoly" ironically has strengthened a monopoly in infrastructure provision markets in Japan. Figure 1 shows that the regulated firms' (called NTT) share expanded with an increase of unbundling usage. ${ }^{9}$

Studies on unbundling regulations in a country that continues the practice is of interest for economists and policymakers, particularly as the United States removed this regulation in the early 2000s. ${ }^{10}{ }^{11}$ Using the Japanese experience and several unique datasets, this paper analyzes the effect of unbundling regulation on the entry decisions of new firms in building infrastructure and market-structure change of infrastructure. In this paper, we show the effects of unbundling on cable television's entry decision into fiber-optic network construction using reduced-form probit models.

\footnotetext{
${ }^{6}$ Cable television companies do not have to lend their fiber-optic lines to other companies at the regulated low cost, but they have to reduce their prices to compete with the regulated companies.

${ }^{7}$ Cable television firms are also able to lend their lines to non-facility firms. However, it is not common as there is no public system/regulation to share their lines, their coverage is narrower and the transaction costs to contract with each of them are high.

${ }^{8}$ Both pros and cons exist in the effort to generate competition in infrastructure: On the one hand, competition generates technological innovation and excludes the price increase associated with monopolies. However, the existence of two facilities in an area costs more and causes over-investment.

${ }^{9}$ Regulation usage is measured by the number of unbundling-user firms at the municipal level.

${ }^{10}$ We should keep in mind that, contrary to Japan, the U.S. quit unbundling claimed by incumbent telecommunication companies, but the deregulated incumbents have not caught up with cable TV firms, and lose their share in home fiber.

${ }^{11}$ The Berkman Center at Harvard University surveyed international differences on how unbundling affects fiberoptic networks, on behalf of the FCC. The FCC also visited Japan several times to investigate the regulation of fiberoptic lines. These surveys are reflected in the U.S. National Broadband Plan.
} 
Second, this paper assumes a dynamic game of infrastructure construction, models the behaviours of the three types of players (regulated firms, unregulated firms and firms borrowing the unbundled facilities), and estimates the effect of unbundling on the profits of new entrants. Then, using the profit parameters from the dynamic structural estimation, this paper evaluates the unbundling effects by counterfactual analysis. In both the reduced-form and structural estimations, we find negative effects of unbundling on entry decisions for new builders of alternative networks. In the counterfactual analysis, unbundling decreases new entry into the markets to provide infrastructure by $24 \%$. This empirical finding suggests that unbundling regulation during periods when new technology is being diffused decreases competition in the infrastructure market.

This paper proceeds as follows. Section 1 offers an overview of the related literature. Section 2 discusses unbundling regulation and the Japanese experience with infrastructure competition and fiber-optic penetration. The datasets to be used in this study, their management and their characteristics are presented in Section 3. In Section 4, the evidence from reduced-form probit regressions is provided. The dynamic entry game of infrastructure competition, estimation identification and counterfactual analysis are discussed in Section 5. Section 6 concludes.

$<$ INSERT TABLE 1 and FIGURE 1 HERE $>$

\section{Related Literature}

Traditional microeconomic textbook theory predicts a "trade-off" between facility-based and servicebased competition. The former refers to competition in the building of facilities, while the latter refers to competition for the use of those facilities. It is well known that regulatory authorities cannot stimulate both types of competition, because there would be no incentive to build facilities if the regulators opened those facilities to encourage competition in service markets. However, empirical research on this subject is uncommon because the building new of infrastructure in the presence of unbundling regulation is rare and micro-level data are unavailable.

Recent theoretical papers on unbundling analyze the price and usage effects of unbundling on the installation of infrastructure. Jorde, Sidak and Teece (2000) find that the usage of unbundling decreases investment, and Bourreau and Dogan (2005) and Hori and Mizuno (2006) examine regulation-price effects on infrastructure competition. Bourreau and Dogan (2006) also claim that unbundling delays technology adoption. These theoretical papers suggest that unbundling regulations reduce investment and competition in building infrastructures. On the other hand, Cave (2006) and Cave (2009) propose a new regulation that stimulates both facility-based and service- 
based competition, contrary to the traditional views. ${ }^{12}$

In empirical papers, the literature has considered the pros and cons of unbundling for social benefits. As a positive, Greenstein and Mazzeo (2006) found that unbundling widened the variety of entries in the telecommunications industry after the Telecomommincations Act of 1996 in the United States. Economides, Seim and Viard (2008) find that competition induced by unbundling increases social welfare for low price and high quality services. Conversely, Crandall, Ingraham and Singer (2004) show that existing telecommunication carriers decrease their own investment as a result of unbundling policies. Grajek and Roller (2012) find that access regulation decreases both total industry and individual carrier investment by endogenizing regulations using EU countrylevel data.

In the industrial organization literature, Bresnahan and Reiss (1991) is the seminal paper about the structural estimation of entry and exit models. They analyze market demand and competitive behaviours for a number of firms. Mazzeo (2002) expands this with quality differentiation, and Seim (2006) considers it under an incomplete-information framework. Toivanen and Waterson (2005) also study a multi-plant model. More recently, Aguirregabiria and Mira (2007), Bajari, Benkard and Levin (2007), and Pakes, Ostrovsky and Berry (2007) study dynamic behaviour in entry and exit models, and the applied literature of dynamics such as Collard-Wexler (2012) and Ryan (2012) is rapidly increasing. In the literature of telecommunication studies, Augereau, Greenstein and Rysman (2006) and Goldfarb and Xiao (2011) provide important contributions using entry and exit models. $^{13}$

This paper differs from the previous literature because, first, we analyze whether unbundling regulations prevent new entry into facility construction markets. Provision of natural monopolistic infrastructures is an essential topic for this type of regulation. The results show that the regulations increase the regulated firms' share in infrastructure markets, because unbundling inhibits the building behaviour of new entrants. Second, we use the installation of new infrastructure to identify the effects. The installation of fiber-optic lines to the home is a good case for analyzing the effects: formation of new fiber-optic lines is rare and easily observed. Also, this new infrastructure competition will have a big impact on future industry structures in telecommunications over the next decades. Third, this paper estimates their strategic behaviours using dynamic structural models and evaluates the regulation effects numerically. Entry decisions in natural monopolistic industries are based heavily on dynamic behaviour and strategic interactions with a clear model. We can also seperate the effect of regulation and simulate it by counterfactual policy simulations.

\footnotetext{
${ }^{12}$ However, Bourreau, Dogan and Manant (2010) criticize this type of regulation.

${ }^{13}$ On the other hand, Chipty (2001), Chu, Leslie and Sorensen (2011) and Ho, Ho and Mortimer (2012) consider bundling using structural analysis.
} 


\section{Unbundling and Fiber-Optic Networks}

\subsection{Telecommunications Act of 1996 and Export of the US Regulation}

The Federal Communications Commission (FCC) started the Telecommunications Act of 1996 to promote new entry and competition in the communication industry, mainly by using unbundling regulation. Local-loop unbundling requires specific existing carriers with local premises to lend their facilities to any competitors at a regulated low price. The literature shows that, as a result of fair competition, unbundling regulation decreases prices, increases the variety of services, raises consumer welfare, and provides high quality services, all of which are positive contributions to society. Vogelsang and Mitchell (1997) analyze the regulation scheme. Unbundling regulation was exported outside the United States, under WTO telecommunications law, and unbundling is now imposed in more than 80 countries around the world.

In the U.S., however, regulated firms brought many suits against the regulations. They claimed that the regulation decreased the investment of regulated firms, weakened facility-based competition, and infringed upon their property rights. In response to these claims and judicial decisions, the FCC amended some of the regulations. Particularly, the FCC addressed the delay in providing fiber to the home (FTTH). To encourage the diffusion of fiber-optic networks, the FCC, in 2003, decided to remove unbundling regulation on fiber-optic lines. Whether this decision by the FCC was good for social welfare is still under discussion. Firms that use unbundling are petitioning the FCC to reverse its deregulation of unbundling on fiber-optic lines. Similar controversies exist in Asia and Europe.

\subsection{Fiber Technology and the Market Structure}

Unlike the United States, Japan is a country that has faithfully adhered to the unbundling regulation on both fiber and metal lines. Unbundling regulations were first introduced in 1997, and the Telecommunications Business Act in Japan required the Nippon Telegraph and Telephone Corporation $(\mathrm{NTT})^{14}$ to lend their local and relay lines, both fiber and metal, to all other firms at a low government-decided rental price. The Japanese government unbundles only the NTT's lines and does not regulate other lines. ${ }^{15}$ Therefore, the regulation is asymmetric.

\footnotetext{
${ }^{14}$ In Japan, a government company offered telecommunication services exclusively as a monopolist until 1985, and the company provides fair, inexpensive and high-quality services to the whole nation. However, competition was needed to induce lower costs, wider variety, and flexible services.

${ }^{15}$ Cable television companies can voluntarily rent their lines to other companies, but user companies have to contract with each small CATV and the transaction cost is higher than NTT. Currently, most of the CATVs do not lend their
} 
In 1985, the former government monopoly for telecommunications service was privatized and became the NTT. In the same year, several firms entered the market as a result of the liberalization. The NTT inherited most of the monopolistic premises as a "gift" from the government and made a substantial profit for an extended period. After 1985, the NTT was divided into several firms, and, by 2011 , cable television companies, electrical utilities etc. had also built their lines and offered wired telecommunications business.

Fiber to the home (FTTH) is a new technology that provides higher bandwidth. Compared to traditional metal lines, fiber lines transmit signals at higher speed, with less loss of information and with lower maintenance cost. Internet service providers in Japan began offering 1 Gbps services using FTTH in 2011. FTTH is a promising technology and the transfer speed of fiber lines can be improved with technological progress, while drastic improvement in metallic-line service seems unlikely.

In telecommunications, backbone networks are formed first. Stations are built in each area, and the backbones between stations are linked to transfer large amounts of information. Next, individual lines are built from stations to each unit, such as homes and offices. Therefore, when each unit interacts online, it connects to the closest station first, then the signal is sent via the backbone network to the station nearest the counterpart's unit and finally the signal is transferred to the destination unit.

The wired network between station and home is assumed to be a natural monopolistic infrastructure: only a few will provide this due to its huge sunk cost. Compared to this, the demand for backbone networks is high and these networks are less costly to build than station-to-home networks. Therefore, several companies typically build backbones and these premises overlap. For many developed countries, by 2000 the backbone networks had been changed from metal lines to fiber lines, but the individual lines from stations to homes/offices remained metal for a long time. In telecommunications, these problems are called "last mile" problems. The FTTH services refer to the services that use fiber between stations and homes/offices and are this paper's main concern. ${ }^{16}$ Unbundling enables firms without station-to-home networks to enter the markets.

\subsection{Diffusion of Fiber-Optic Networks and Battles over Unbundling in Japan}

The diffusion process of home fiber networks in Japan can be roughly divided into three stages. First, in the early 2000s, the regulated firms' (NTTs') share of FTTH service was low. In March

lines to others.

${ }^{16}$ We use the term FTTH in the sense that it is used by the Ministry of International Affairs and Communication, which includes similar services such as hybrid fiber-coaxial (HFC). 
2002, their share was $25.6 \%$, and cable television (CATVs) and electric companies provided strong competition. NTTs had metal telephone lines, CATVs had metal CATV lines, and electric companies had their own electric lines. Therefore, it was easy to install fiber-optic lines next to their pre-existing lines for NTT, CATVs and electric companies. CATVs and electric companies entered the fiber market to earn profits from services such as high quality IP-phones, high definition TV programs, and high speed internet. During this period, NTT's infrastructure competitors preferred unbundling regulations because such regulations were expected to decrease NTT's investment in fiber networks, in turn allowing competitors' shares in the fiber market to increase.

In the middle of the decade, however, CATVs and electric utilities decreased their investments or stopped building FTTH, because non-facility service providers entered the market using regulated NTT premises. These new firms took CATVs' and electric utilities' potential customers. Also, even if CATVs were to build their own fiber lines, they would have faced harsh price competition, since NTT premises have to be shared at a regulated low cost. Furthermore, the service providers strongly demanded that the government reduce the rental price and increase the flexible usage of the facility: service providers estimated and claimed the rental cost should be 690 yen per fiber line a month, significantly different from the preset rental cost of 5094 yen. Conflicts over the conditions and prices of fiber lines between the NTT and service providers involved the Ministry of Internal Affairs and Communications (MIC), the Japan Fair Trade Committee (JFTC), the courts, politicians, lawyers, and economists. In the battles between NTT and service providers, CATVs and electric companies always filed petitions with the MIC stating that the unbundling regulation decreased their incentive to enter the fiber-optic line market and increase investment. They claimed that unbundling only favors the service market in allowing "fair" competition, but negatively affects competitors in facility-based markets.

Finally, by the end of the 2000s, NTT's share of fiber lines was around 75\%; they dominated the fiber facility market, eliminating other firms under unbundling regulation. A few CATV companies have started to borrow fiber lines from NTT, rather than build lines themselves. ${ }^{17}$ This market structure was heavily criticized by both service providers and facility competitors facing a monopolistic situation. The MIC is discussing the divestiture of the operation of fiber lines from NTT. However, NTT and their stockholders are heavily opposed to the idea because NTT has already invested enormously to install fiber lines, and the infrastructure is one of the important sources of profits for NTT.

\footnotetext{
${ }^{17}$ In general, CATVs do not share their lines with other firms. This is because there are only small economies of scale in the CATVs' size, and companies tend to be small. So, if user firms want to borrow lines from CATVs, they have to negotiate for each customer. This significantly increases transaction costs. Electric companies cover wider areas and sometimes lend their lines to other firms. However, compared to NTT and the government regulation system, their share of lines is small.
} 
This paper models their strategic behaviours, empirically estimates their profits and costs from available datasets, and assesses numerically whether unbundling regulations prevent new entries in the facility market and whether it induces regulated firms' monopolization.

\section{Data Description and Variables Construction}

\subsection{Data Sources}

This paper uses four datasets and matches them at the municipal level. The first set is data on the use of unbundling regulation. NTT East, a unique, regulated carrier in eastern Japan, provides data on the number of companies that used NTT's fiber-optic facility at the station level between 2005 and 2009. ${ }^{18}$ The number of stations that NTT upgraded to fiber lines is also taken from these data. $^{19}$

The second source is the entry and exit data in FTTH building markets. The Ministry of Internal Affairs and Communications (MIC), a Japanese regulation authority, provides an information and communications statistics database. Using these figures, we can detect which companies built fiber-optic premises between a station and a home in a prefecture at a monthly interval. Therefore, we can identify when, where, and which firms built FTTH. ${ }^{20}$

The third dataset reports figures that examine CATVs and their coverage area. The Regional Broadcasting Division in the MIC provides facility data on CATVs at the municipal level. Using this dataset, we can identify which CATVs enter which market. Combined with the second FTTH dataset, we can deduce which CATVs built FTTH in which markets. ${ }^{21}$ Most firms that build fiberoptic networks provide HDTV programs via fiber lines. ${ }^{22}$

The fourth dataset covers market characteristics. We use population, area, and income at a market level. The population and area data are taken from the 2005 census, and income data are taken from a tax division of the MIC.

\footnotetext{
${ }^{18}$ NTT West does not publish these data, so we exclude the sample in western Japan.

${ }^{19}$ The usage data that NTT provided cover the following dates: 2005/01/31, 2006/03/31, 2007/03/31, 2008/04/30 and 2009/03/31. We assume that the interval difference in the data does not affect the main results.

${ }^{20}$ The MIC changed its regulations in 2003 and firms can now build their lines freely. However, if they offer or stop those services, they must register with the MIC. The MIC records that information and announces officially when and which firms offer what kind of services in which area. We used these registration data for this study.

${ }^{21}$ When the CATVs enter the market, they often offer their services to all of their coverage area, on the request of application from customers. We assume therefore that CATVs offer the fiber service to all of their coverage area.

${ }^{22}$ Most companies that build fiber lines offer TV program services. If there are some firms that do not offer it, we assume that those are reflected in the market dummies. The data include firms such as TEPCO (operated by the Tokyo Electric Power Company) and JCN (operated by KDDI).
} 


\subsection{Construction of Variables}

\subsubsection{Definition of Market}

This paper combines the aforementioned four datasets at the municipal level. The municipality is the smallest definition of a market that we can construct from public datasets. The data are taken from the municipality as it existed in April 2009. ${ }^{23}$ After eliminating outliers at the 95\% significance level, ${ }^{24} 933$ municipalities existed. ${ }^{25}$ The reason we use municipal-level data is twofold. First, in our model of an entry game, we assume symmetric firms. If we use a larger definition than the municipal level, it is possible that the assumption of a symmetric firm size is false. For example, if we use a larger definition of a market, it is possible that 10-20 CATVs enter in one market, but their actual sizes might be very different. If we divide large firms into small areas, we can assume similar symmetric size in each area. Most markets contain zero to two CATVs, so this would be reasonable. Second, this paper considers competing networks between CATV firms. In other words, we assume consumers can choose fiber-optic lines from a few options, such as from a regulated carrier (NTT) and one or two CATVs. If we use a larger region size, the consumers' choice set is different from the actual one. ${ }^{26}$ Using the municipal market definition, in more than 95\% of the markets, the consumer has a choice between 0 and 1 CATV to choose from for FTTH services, and this is plausible, considering the actual consumers' choice set in Japan. Table 2 shows the number distribution of CATVs that build their own fiber lines.

\section{$<$ INSERT TABLE 2 HERE $>$}

\subsubsection{Usage of Unbundling Regulation}

One of the key variables in this paper is the usage of unbundling regulation. Because we cannot get direct data on the quantity in each market, we use this number as a measure of unbundling regulation usage. ${ }^{27}$ We take two variables from this dataset: usage of "station to home" fiber-optic networks and usage of "station to station." The "station to home" usage is our main concern, which is the usage of fiber-optic networks between the core network and the home/office; this is a natural

\footnotetext{
${ }^{23}$ There were many mergers of municipalities in Japan from 2005-2009, and we reconstruct the data using the definition in 2009.

${ }^{24}$ We exclude outliers by number of families, area, income, usage level and station level.

${ }^{25}$ We excluded Niigata and Kamiku Isshiki because they do not fit the definition of a municipal market in April 2009.

${ }^{26}$ It is not realistic to have consumers choosing their FTTH services from among 10 CATVs in the telecommunication industry. In reality, they often do not compete with each other.

${ }^{27}$ In the structural estimation, we relax this condition and model entry behaviours of unbundling-user firms.
} 
monopolistic infrastructure in telecommunications. In each market there are several stations (the average is 3.66). The maximum number of service providers for each station in the market is taken as the market's usage measure, assuming some big firms use all stations in the municipality.

Researchers typically evaluate the effects of regulations by comparing the status before and after the introduction of regulation. Otherwise, they compare an area where a regulation is adopted with one where it is not. Furthermore, they compare the areas where the strength of regulation is different. We take this third way to evaluate the unbundling on fiber lines. The regulation system of unbundling itself is the same all over eastern Japan: the regulated firm (NTT) has to lend all its facilities to every applicant at the same rental price determined by the regulatory authority. However, the usage level is different in each market. In Figure 2, we observe that the number of service providers is different for each municipality, even if the municipalities have similar population sizes and densities. There are several sources that contribute to this variation. One of the main sources is the cost difference in each market. It costs a lot to build a fiber-optic network in some rural areas that have a low population density or are isolated by mountains or seas. Even in some urban locales, if the telephone/CATV lines are underground, the cost of building a fiber-optic network is higher compared to installation via telephone poles. Therefore, in relatively low rental price markets, firms are more likely to use regulated firms' premises and the number of service providers will be higher. Variation in usage, given market characteristics (such as the number of regulated firms' fiber stations, the number of households, population density, and the like), reflects the relative importance of the regulation across markets. Figure 3 shows the markets of eastern Japan. There is substantial variation in the types of markets: rural and urban areas, small and large area, islands and mountains.

\section{$<$ INSERT FIGURE 2 and FIGURE 3 HERE $>$}

\subsubsection{Building Fiber-Optic Networks}

Our main interest is to analyze whether CATVs built their own fiber networks between station to home: the natural monopolistic infrastructure. The Information and Communications Statistics Database in the MIC maintains records of which companies build networks in which prefecture. Further, the MIC's Regional Broadcasting Division Database can identify in which municipality the CATVs operate. By connecting these two, we can observe when and in which market CATVs built fiber-optic networks. Because we only have firm/prefecture level fiber-optic entry and municipal-level CATV activity, we assume that CATVs decide to enter at the prefecture level on their own networks. Since most CATVs cover a few markets, we think this is a plausible assumption. 
NTTs, the regulated carriers, also built a fiber-optic network that covered most of Japan: NTTs did not offer coverage to only 2 markets in eastern Japan. ${ }^{28}$ NTTs' dataset shows how many stations NTTs installed with fiber optics. This number of stations correlates to the number of fiberoptic lines. However, the number of stations also depends on population density. More stations are needed in a low density area than a high density area, even if the number of lines offered is equal. Considering this aspect, we added the logarithm of area in the estimation equation.

The fiber-optic network technology is slightly different between CATVs and NTT. NTT uses the fiber to the home (FTTH). Most CATV's technology uses both hybrid fiber coaxial (HFC) ${ }^{29}$ and FTTH. The two technologies are similar. The difference lies in that HFC uses fiber lines to connect the core network to a building area, and then uses metallic lines after this point, while FTTH uses fiber lines entirely. The HFC has a slightly lower data transfer rate than the FTTH, but both offer similar speeds and thus compete with each other. ${ }^{30}$

\subsubsection{Market Characteristics}

Because the decision to build a fiber-optic network depends on market factors, we use several market characteristic variables. The variables can be grouped into two categories: demand and cost factors. Demand factors include the number of households and average income. The number of households measures the potential number of lines in a market. Ordinarily, one fiber line is installed per household. Average income, defined as aggregate income divided by population in each market, measures the wealth of the market; richer markets may have greater demand for fiber-network premises. Area is included as the primary cost factor, since it costs more to install fiber in lower density markets. All market variables are fixed for a calendar year because higher frequency data are unavailable and also because they do not change much from year to year. ${ }^{31} \mathrm{We}$ take the number of households and area from the 2005 Japanese census. Income is taken from the tax division of the MIC for 2008. Assuming the effects of these market characteristics are concave, we take the $\log$ of all variables, after adding 1 to avoid an infinity problem. ${ }^{32}$ Tables 3 and 4 summarize the sample statistics.

\section{$<$ INSERT TABLE 3 AND TABLE 4 HERE $>$}

\footnotetext{
${ }^{28}$ We deleted the markets in which NTT does not offer fiber.

${ }^{29}$ This is called HFC HTTB or HTTC.

${ }^{30}$ In Tokyo in June 2010, the NTT's FTTH offered 200 Mbps for 6720 yen per month and J:COM (one of the CATVs) offered $160 \mathrm{Mbps}$ for 6300 yen per month.

${ }^{31}$ In the estimation of the dynamic game, we can reduce the state space by fixing unchanging variables.

${ }^{32}$ For example, it is likely the case that once income passes some threshold, demand will flatten out. By taking a $\log$, we can decrease these effects.
} 


\section{Results of Reduced-Form Models}

\subsection{Probit Models}

\subsubsection{Unbundling Effects on CATVs' Fiber Networks Building Behaviours}

First, we consider how much the usage of unbundling affects the entry of CATVs into fiber-optic network building markets, using probit models. We assume the following estimation equations with an IV probit model and consider how unbundling usage affects the building of fiber-optic networks by CATVs. The area where unbundling usage is high, given other market characteristics, will be the one where unbundling regulation is strong. If so, CATVs would build fewer fiber lines in such markets. To check this, we assume the following estimation equation:

$y_{m t}=1\left(y_{m t}^{*}=\beta_{0}+\beta_{1} \times\right.$ usage $_{m t}+\beta_{2} \times$ Incumbent $_{m t}+\beta_{3} \times$ station $\left._{m t}+\mathbf{X}_{m t} \beta_{4}+d_{t}+\varepsilon_{m t}>0\right)$

where $y_{m t}$ takes a value of 1 if there is entry by CATVs into the fiber-optic building market at market $m$ in year $t$, otherwise 0 . The variable $u_{s a g e}$ is the logarithm of the number of firms that used the NTT's regulated facility between station to home, which is our main variable of interest. $^{33}$ station $_{m t}$ is the number of stations at which regulated firms (NTT) adopted the fiberoptic lines. We use this variable as a measure of the quantity of NTT's line. This variable is for distinguishing the unbundling usage effects from NTT's competitor effects in infrastructure markets. Market characteristic variables, such as number of households, area and average income, are represented by $\mathbf{X}_{m t}$. We added the number of metal CATVs to adjust the ease with which they can build fiber lines in the market. Also, the number of current incumbents (CATVs) in the market that had previously built fiber-optic lines is shown as Incumbent $t_{m t}$. $d_{t}$ is the year dummy. Assuming the effects of these variables are concave, we take the log of $u_{s a g e}$, station $_{m t}$ and market characteristics, after adding 1 to avoid an infinity problem. ${ }^{34}$

Unobservable market characteristics may affect CATV's fiber-building behaviour. Also, the CATV's home fiber may decrease the unbundling usage and this generates a reverse causality problem. Considering the endogeneity in $u_{s a g e}$, we take the number of firms that used the

\footnotetext{
${ }^{33}$ Another specification may be to use the rates of usage per stations $\frac{\text { usage }_{m t}}{\text { station }_{m t}}$, rather than using $u s a g e_{m t}$ itself, to distinguish the unbundling effects from the staion effects. However, we are taking logs, so those effects will be absorbed in the station coefficient. (Ex. $\beta_{1} \times \frac{\text { usage }_{m t}}{\text { station }_{m t}}+\beta_{3}$ station $_{m t} \rightarrow \beta_{1} \log$ usage $_{m t}+\left(\beta_{3}-\beta_{1}\right) \log$ station $_{m t}$ ) We can make a similar statement for the $\frac{\text { usage }_{m t}}{\text { population }_{m t}}$ specification.

${ }^{34}$ We do not take a log for Incumbent ${ }_{m t}$, because most observations are 0 or 1 , with a maximum of 3.
} 
regulated facility between station to station as the instrument. When firms with no facilities enter into the market, they typically use both station-to-home facilities and station-to-station facilities. Some firms use just station-to-home lines; these are called bottleneck facilities, because some of them already have station-to-station facilities. Therefore, the usage of station-to-station facilities is related to the usage of station-to-home facilities. However, the decision of CATV firms whether to build lines between station and home should be unrelated to the usage of the facilities between station and station, because the station-to-station usage will not substitute for the lines between home and station. We use this as an instrumental variable. ${ }^{35}$

The results are in the first column of Table 5. We observe a significant negative coefficient on unbundling usage. Most of our estimates are significant with the predicted sign. Only the coefficient on the number of regulated firms' stations was not significant. From these results, we can compute the marginal effects of unbundling usage on a CATV's likelihood of building fiber lines: a $1 \%$ increase in the number of service providers decreases by $4.31 \%$ the probability of new entry of CATVs into the building market for home fiber-optic lines.

\subsubsection{Unbundling Effects on Regulated Firms’ Fiber Networks Building}

We also analyze how the unbundling systems affect the regulated firms' building behaviour with respect to the building of new home fiber networks. We use settings similar to those of CATVs. The main difference is that we change the dependent variable to how many new fiber stations NTT built in the market. The second column of Table 5 shows the results of the ordered probit model. ${ }^{36}$ In the results, there are no significant effects of unbundling usage. However, we should keep in mind that this result uses the full sample, and there are significant positive effects in urban areas as shown in the next section.

$<$ INSERT TABLE 5 HERE $>$

\subsection{Robustness Checks in Reduced-Form Regressions}

In this section, we consider three types of robustness checks on the above results.

\footnotetext{
${ }^{35}$ In a robustness check, we consider previous usage ${ }_{m t-1}$ for $u s a g e_{m t}$. Also, we checked the endogeneity in station $_{m t}$ using the instruments as station $_{m t-1}$. In both case, we got robust results.

${ }^{36}$ In an ordered probit model, there is no popular way to estimate with instrumental variables. So, we estimate the ordered probit model without instruments. Also, we cut the metal CATV, because it will not affect the behavior of the NTT. Furthermore, we do not add a constant in an ordered probit model.
} 


\subsubsection{Monopoly Settings}

First, we check monopoly settings. We use the municipal-level market definition in the above estimation. The municipal-level market is the smallest definition of a market possible given the data constraints. The number of CATVs is less than three in most markets in our data, and it is plausible that consumers do choose between one or two CATVs. However, it could be possible that the CATVs do not compete with each other, for example, if two CATVs build fiber lines in a municipality, but CATV A builds in the west and CATV B in the east. Then, our specification may have a problem. To check for this problem, we reestimate using only municipalities where zero or one CATV offered service for the entire sample. The results are in the first column of Table 6. There are little changes from the base results in Table 5.

\subsubsection{Instrumental Variables}

Second, the validity of the instruments may be questioned. We attempt to account for the endogeneity of usage between home and station premises using usage between station and station as instruments. There is the possibility of reverse causality in that CATV construction of home fiber lines could decrease the usage of station-to-station. Because of this, we use past usage of stationto-home as instruments. In the second column of Table 6, we confirm that there is a negative effect. We also consider the endogeneity of station $_{m t}$ using station ${ }_{m t-1}$ as instruments in the third and fourth columns of Table 6 . The results are robust to these changes.

\section{$<$ INSERT TABLE 6 HERE $>$}

\subsubsection{Urban Area Differences}

Third, we analyze whether the unbundling effect is differs across subsamples based on population density. Unbundling is likely to have larger effects on fiber-line builders' behaviour in urban areas. This is because competition is keen and there is a high probability that several builders install fiber lines within the city. We select the upper $33 \%$ of areas by population density and analyze the results for the same basic model. Table 7 shows the results. For high density urban areas, the unbundling effects on CATVs are still robust and similar in magnitude to those of the full sample. However, the effect on regulated firms' behaviour is significantly positive in these areas. ${ }^{37}$

\section{$<$ INSERT TABLE 7 HERE $>$}

\footnotetext{
${ }^{37}$ In the non-urban areas, the estimation results are also similar to the basic results in the previous section.
} 


\section{Assessing Unbundling Effects by a Dynamic Game}

\subsection{Estimation of a Structural Dynamic Entry Game}

In comparison to previous sections, here we consider the estimation of a structural dynamic entry game. By modeling competition in building fiber-optic networks using a dynamic game, we incorporate several important features. First, we can estimate dynamic strategic behaviours between infrastructure-building firms and firms that borrow those infrastructures. For example, CATVs' decisions to build fiber lines relies heavily on how much regulated firms built fiber lines and how much the lines are used by other firms, and vice versa. We model and estimate their endogeneously interactive behaviours from actual outputs using equilibrium conditions of the model. Furthermore, it takes a long time to build infrastructure, and the telecommunications industry has oligopolic characteristics due to its huge sunk costs. Therefore, the entrants forecast future monopolistic profits before making the decision to build a fiber-optic network facility. These can be estimated by a dynamic structural model but not in the static models with no uncertainty.

Second, via this structural method, we can estimate unknown parameters that ordinary reducedform estimation methods cannot. The data are limited to entry and exit data of fiber-optic networks, the usage of unbundling regulation, and market characteristics at the market level. Using these data, we confirmed the effects on the entries in previous sections. However, by imposing certain economic assumptions, we can estimate the mechanism through which the regulation affects entrants' behaviours via their profit maximization; structural estimation can estimate how much their profits from constructing infrastructure decrease with unbundling. Also, several concerns with the previous results can be tested with this type of estimation of a clear model. The regulated company, NTT, is bigger than the small cable television firms, so NTT may have cost advantages of installing fiber lines. Also, cable televisions' main technologies are HFC (hybrid fiber coaxial): this can be installed at a lower cost, but the speed is also a bit slower than FTTH. These two technologies are competing, but some effects may come from this difference. In the structural estimation, we clearly model their type difference in a dynamic game: each has different markets, cost and profit systems, but they are competing with each other. ${ }^{38}$

Third, these estimates also have significant values when designing regulation. In the previous reduced-form estimation, we cannot rationalize why unbundling decreases new entry. We can, however, value the policy change with microfoundation by counterfactual simulation, using the estimated parameters. In other words, modeling related players' behaviours, we can quantify how

\footnotetext{
${ }^{38}$ Our model is a 3-type dynamic version of Mazzeo (2002), who considers entry behaviours of different types in competing markets.
} 
much unbundling decreases profits of fiber-line builders, and how much this lost profit will change their entries. Then, we can predict the outcomes of policy changes.

\subsection{Framework}

There are $m \in\{1,2,3, \ldots, M\}$ independent geographic markets and $t \in\{1,2,3, \ldots, \infty\}$ discrete infinite time periods. Here, the unit for $m$ is a municipality and for $t$ is one year. There are three type of players $\tau \in\{C A T V, N T T$, Service Provider $\}$ : the regulated carrier, NTT, and CATV firms compete to build "station-to-home" fiber-optic networks in market $m$. Also, service providers borrow fiber lines from the NTT through an unbundling system. Therefore, this is a 3-type player dynamic game and analyzes how they affect each other. ${ }^{39}$ CATVs decide whether to build stationto-home fiber lines to their clients or not, NTT decides whether to build station-to-home fiber-optic lines in its stations or not, and service providers decide to enter the markets using NTT's facilities. Their strategic behaviours affect each other. Because exit from offering fiber-optic services is very rare in the diffusion periods, we limit the firms' option to whether they enter or not. We deleted those markets where firms exit a fiber-optic network construction. ${ }^{40}$

The timing of the game is as follows. First, at the beginning of each time period t, NTT, CATVs and service providers observe: 1) the number of CATVs that have already constructed fiber-optic networks; 2) the number of stations for which NTT has already adopted a fiber-optic network; 3) the number of service providers of NTT's facilities; 4) market characteristics; 5) market fixed effects and 6) current year. Second, CATVs decide whether or not to build a fiber-optic network in the market, NTT decides whether or not to build its fiber-optic network in additional stations, and service providers decide whether or not to enter into the markets using unbundling. These decision are all made simultaneously. Third, entrant CATVs pay costs, and NTT also pays a cost if they decide to increase lines (stations) for fiber-optic networks. ${ }^{41}$ At the end of each period, all three types of players get profits from operating their business. After profits are realized, market states evolve to the next period. We should keep in mind that this model assumes a one-year "time-to-build": CATVs and NTT pay the building cost at time $t$, but they will earn profits after $t+1$.

\footnotetext{
${ }^{39}$ A dynamic version of Mazzeo (2002).

${ }^{40} \mathrm{Also}$, the decrease in the number of fiber-optic stations is vey rare: $1.6 \%$ of all observations. To estimate credible values, we do not estimate the sell-off values on exit.

${ }^{41}$ Service providers pay just operating cost and do not pay the entry sunk cost, because they can enter the market using regulated firms' facilities.
} 


\subsection{State and Action Variables}

In recognition of the competition to build fiber-optic networks, we define four state variables: the number of fiber-built CATVs, the number of fiber-built NTT stations, the number of service providers of NTT fiber-facilities, and a year dummy. We assume that the first three are endogenous state variables determined by the model, while the year dummy is an exogenous state variable determined outside the model. ${ }^{42}$ We discretize the variables to reduce the state space: there are 15 values for the number of NTT's fiber-built stations, and 15 values for the number of service providers. There are 4 states for the number of fiber-built CATVs (0,1, 2 and 3$)$ and a 4-valued year dummy. Therefore, the total state space is $4 \times 15 \times 15 \times 4=3600$. $^{43}$

Endogenous state variables evolve within the model and their transition probabilities are determined by the rational profit-maximizing behaviour of CATVs, NTT and service providers. Compared with these, year dummies are determined exogenously: they increase over time but stop after 4 years. These transitions are common knowledge for players.

We assume that action variables are binary. For CATVs, it is whether or not to build stationto-home fiber-optic networks for their clients. For NTT, it is whether or not to increase stationto-home fiber-optic stations. For service providers, it is whether or not to enter the market using NTT's home fiber-optic networks.

\subsection{Unobservable Heterogeneity}

One of the important concerns for the relationship between CATVs' entry and usage of NTT's facilities is unobservable heterogeneity. If there are some unobserved market characteristics, the estimated results may be biased. For example, if for some reason markets have difficulty installing fiber-network facilities, this causes an increase in the usage of installed lines and a decrease in entry by CATVs. To avoid this unobserved market heterogeneity, we add market fixed effect variables. To address this, we use a two-stage fixed approach. This approach is similar to that in other papers such as Lin (2011) or the related literature. First, we take the average number of entrants for fiber

\footnotetext{
${ }^{42}$ Our paper examines the building of fiber lines. However, we consider the case in which unbundling usage is endogenous.

${ }^{43} \mathrm{We}$ can consider other specifications of the state spaces. The baseline specification limits the state space for key variables, considering that we have about 4000 observations. Our main interest is the relationship between CATVs' behaviour, NTT's behaviour, and regulation usage. We also add year effects for technological innovation and demand change over time. This means that we do not differentiate value functions by those market characteristics. However, Agguiregabira (2009) uses similar settings (even more restricted state-space cases) and replicates good results for twotype dynamic entry models. We also calculate under the setting with more state variables as far as computing facilities allow, such as discretized population, and area. However, the estimated results are similar.
} 
CATVs and NTT's fiber stations for each market. By regressing them on market characteristics, we get residuals for each market. We discretize the residual for four bins and get dummies to adjust the level of unobserved profitability. In the second stage, we add the dummies to the per period payoff function to remove the unobserved heterogeneity bias.

\subsection{Spurious Relationship}

In the diffusion process, key variables such as usage of unbundling, NTT's fiber stations and entry of CATVs often increase simultaneously. There is the possibility of a spurious relationship. Further, in the diffusion of new technology, the technology cost to install fiber lines will fall over time, and demand for them will increase even if other market characteristics are the same. To remove these effects, we add year dummies in the profit function. They increase with year and stop in $2009 .^{44}$

\subsection{Per Period Payoff Function}

We assume a linear and reduced-form payoff function. Linear forms require less computing time and are also a common approach in the literature.

$$
\pi_{i m t}^{\tau}=\underbrace{X_{m t} \beta_{X}}_{\text {Revenues of FTTH service }}-\underbrace{Z_{m t} \beta_{Z}}_{\text {Costs of FTTH service }}-\underbrace{g\left(N_{-i m t}^{\tau}, N_{-i m t}^{-\tau}\right)}_{\text {Competitors' effect }}-\underbrace{G_{m t} \beta_{G}^{\tau}}_{\text {Regulated usage effect }}
$$

where $\pi_{i m t}^{\tau}$ is the profit of offering FTTH services of firm $i$ of type $\tau$ at market $m$ in year $t . X_{m t}$ is demand factors of the market (number of households and average income), $Z_{m t}$ is cost factors of the market (area), $g\left(N_{-i m t}^{\tau}, N_{-i m t}^{-\tau}\right.$ ) is the competitors' effect of similar services (number of other CATVs, number of fiber stations of NTT and number of service providers), and $G_{m t}$ is the effect of unbundling regulation (regulation usage). These variables are the same as in previous sections. We assume that CATVs and service providers are symmetric and that the size of NTTs' stations are also identical, and the number of NTTs' stations can be thought as the measure of quantity. ${ }^{45}$ These firms conduct a Cournot-type competition, and the actual regulatory access rates are already reflected in the usage of unbundling. We assume that CATVs and NTT pay a sunk cost to enter and get zero profit if they do not enter.

\footnotetext{
${ }^{44}$ The reason it stops is for the limitation of the data.

${ }^{45}$ These assumptions reflect the approach used in the previous literature of entry and exit models.
} 
For the competitor effect, $g^{\tau}\left(N_{-i m t}^{\tau}, N_{-i m t}^{-\tau}\right)$, we do not assume proportional effects because the first competitor's effect is larger than the second competitor's in CATV competition. ${ }^{46} \mathrm{We}$ also assume that the CATVs' entry, NTTs' construction and service providers' entry all affect each other. Reflecting these assumptions, the function of $g^{\tau}\left(N_{-i m t}^{\tau}, N_{-i m t}^{-\tau}\right)$ becomes the following:

$$
\begin{aligned}
& g^{\tau}\left(N_{-i m t}^{\tau}, N_{-i m t}^{-\tau}\right)=\beta_{1}^{C A T V} \times \text { presence of first CATV that built FTTH } \\
& +\beta_{2}^{C A T V} \times \text { presence of second CATV that built FTTH } \\
& +\beta_{3}^{C A T V} \times \text { presence of third CATV that built FTTH } \\
& +\beta_{4}^{N T T} \times \# \text { of NTT's fiber stations } \\
& +\beta_{5}^{\text {Service Provider }} \times \# \text { of service providers }
\end{aligned}
$$

\subsection{Firm behaviour and the Markov Perfect Equilibrium}

Under the above assumptions, CATVs, NTT and service providers simultaneously choose their actions to maximize the present value of the sum of future profits. We can define their value function as follows,

$$
V\left(S_{i t}\right)=\max _{a_{i t}^{\tau} \in A} E\left[\pi_{i t}^{\tau}\left(a_{i t}^{\tau}, S_{i t}\right)+\beta \int V\left(S_{i t+1}\right) d F\left(S_{i t+1} \mid S_{i t}, a_{i t}^{\tau}\right)\right]
$$

where $a_{i t}^{\tau}$ is an action variable of firm $i$, type $\tau$ and time $t . S_{i t}$ is the set of state variables for firm $i$ and time $t$. Following the previous literature, we assume that the discount factor $\beta$ is 0.95 because the data are annual. A Markov strategy is a mapping $\sigma_{i}\left(S_{i t}\right) \longmapsto\{0,1\} \in A_{i t}$, where $A_{i}$ is the firm's action set. If CATV firms enter the market or NTT increases the number of fiber stations, it is 1 ; otherwise, 0 .

We can rewrite the above value function, conditional on the strategy,

$$
V\left(S_{i t} \mid \sigma\right)=E\left[\pi_{i t}^{\tau}\left(\sigma, S_{i t}\right)+\beta \int V\left(S_{i t+1} \mid \sigma\right) d F\left(S_{i t+1} \mid S_{i t,} \sigma\right)\right]
$$

Then a set of Markov strategies $\left(\sigma^{*}\right)$ is a Markov perfect equilibrium if and only if, for all $i$,

\footnotetext{
${ }^{46}$ Compared to CATVs, we divide NTT's stations and the number of service providers into 15 bins. So, we do not distinguish each incumbent for difficulty of the estimation.
} 
$S_{i t}$, and alternative strategies $\sigma_{-i t}^{\prime}, \sigma^{*}$ satisfies

$$
V\left(S_{i t} \mid \sigma_{i t}^{*}, \sigma_{-i t}\right) \geq V\left(S_{i t} \mid \sigma_{i t}^{\prime}, \sigma_{-i t}\right)
$$

\subsection{Estimation Methodology}

In this paper, we use the Aguirregabria and Mira (2007) [referred to as AM(2007)] nested pseudo likelihood estimation (NPL). AM(2007) has robust characteristics with small sample bias and their method can still find estimates even under the multiple equilibria.

The value function is defined as

$$
V\left(x_{t}\right)=\int \max \left\{\pi\left(x_{t}\right)+\epsilon_{t}\left(a_{t}\right)+\beta \int V\left(x_{t+1}\right) d F\left(x_{t+1} \mid x_{t}, a_{t}\right)\right\} g\left(d \epsilon_{t}\right)
$$

From observable actions, we can construct conditional choice probabilities (CCP),

$$
p_{i t}^{\sigma_{i t}}\left(a_{i t} \mid x_{t}, \epsilon_{t}\right)=\operatorname{Pr}\left(\sigma_{i t}\left(x_{t}, \epsilon_{i t}\right)=a_{i t} \mid x\right)=\int I\left(\sigma_{i t}\left(x_{t}, \epsilon_{i t}\right)=a_{i t}\right) d F\left(\epsilon_{t}\right)
$$

I(.) is the indicator function, and we assume $\epsilon_{t} \sim N(0, \Omega)$.

The nested pseudo likelihood estimator is calculated using the following procedures.

Step 1: Set initial probability. We chose the initial CCP from the dataset, following AM(2007), as

$$
\widehat{P^{0}}\left(a^{\prime} \mid x^{\prime}\right)=\frac{\sum_{t} \sum_{i} I\left(a_{i t}=a^{\prime}, x_{i t}=x^{\prime}\right)}{\sum_{t} \sum_{i} I\left(x_{i t}=x^{\prime}\right)}
$$

Step 2: Given a CPP $\left(P^{k}\right)$, construct the pseudo maximum likelihood function and get the $\theta^{k+1}$ by maximization

$$
\theta^{k+1}=\arg \max _{\theta \in \Theta} \sum_{m} \sum_{t} \sum_{i} \ln \Psi\left(a_{i m t} \mid x_{i m t}: P^{k}, \theta\right)
$$

where $\Psi$ is the choice probability function. 
Step 3: Based on $P^{k}$ and the $\theta^{k+1}$ in step 2, update the probability function according

$$
\widehat{P^{k+1}}\left(a_{j} \mid x\right)=\Psi\left(a_{j} \mid x_{i m t}: P^{k}, \theta^{k+1}\right)
$$

for all $a_{j} \in A$ and $x \in X$.

Step 4: Continuously update Step 2 and Step 3. Referring to Aguirregabiria (2009) and Pesendorfer and Schmidt-Dengler's (2010) non-convergence case, we take the results where $\theta$ mostly converged in the first 50 repetitions.

\subsection{Estimation Results}

Table 8 shows the estimated parameters for the dynamic structural model.

Our main interest is how unbundling usage will affect the building of infrastructures. The unbundling usage-effect coefficient on CATVs' profit was significantly negative, and this indicates that the unbundling decreases the CATVs' profits for building fiber-optic networks. In other words, it decreases CATVs' incentives to build fiber. On the other hand, there is no effect of unbundling usage on regulated firms' profit to build fiber stations, while regulated firms' profit from fiber stations increase service providers' profits.

For other variables, the coefficient of CATVs' existence is negative, but most are not significant. As predicted, the costs to build natural monopolistic infrastructures are significantly negative with comparatively large magnitude, and this factor explains a large part of the profits and building behaviours. On the market characteristics, a significant positive sign of regulated firms' area reflects the fact that regulated firms have to build more fiber stations in a wider area. The significantly negative sign on service providers' income may suggest that low-income households prefer service providers using unbundled infrastructure, because many those service providers offer inexpensive services.

\section{$<$ INSERT TABLE 8 HERE $>$}

\subsection{Counterfactual Analysis}

How much does unbundling affect behaviour in construction markets? Using the estimated parameters, we can quantify the effect of the regulation by counterfactual analysis. 
This paper applies the methodologies used in Aguirregabiria (2012) and Aguirregabiria and Ho (2012). We calculate the counterfactual conditional choice probabilities using the following Taylor-series approximation:

$$
\widehat{P}_{m}^{*}=\widehat{P}_{m}^{0}+\widehat{P}_{m}^{0} *\left(\mathbf{1}-\widehat{P}_{m}^{0}\right) *\left(\widetilde{z}_{m}^{0}\left(\theta^{*}-\widehat{\theta}_{0}\right)\right)
$$

where $\widehat{P}_{i m}^{*}$ is the counterfactual conditional choice probability in market $m, \widehat{P}_{m}^{0}$ is the estimated choice probability, $\mathbf{1}$ is a unit vector, $z_{m}^{\widehat{P}^{0}}$ are regressors under the estimated choice probability, $\widehat{\theta}_{0}$ is the estimated parameters, and $\theta^{*}$ is the parameters under counterfactual assumption.

To remove the effect of service providers on the profits of infrastructure builders, we make the coefficients for unbundling usage in the profit functions of both CATVs and NTT zeros for the counterfactual parameters. ${ }^{47}$ Using the counterfactual choice probabilities from the above equation, this paper simulates how infrastructure builders change their behaviour. We assume that the regulator first decides to quit unbundling in 2005. The results are in Table 9. According to our estimations, if the government had quit unbundling, 24\% more CATVs would have built FTTH. Compared to this, regulated firms decrease the number of fiber stations by around $0.6 \%$.

One possible extension of this analysis would be to consider the expectation of infrastructure builders in the counterfactual analysis. For example, after the government quits unbundling in order to induce investments and infrastructure competitions in diffusion periods of new technology, it has an incentive to restart unbundling once the new technology has prevailed. If infrastructure builders expect this change in the regulator's policy, the effect of quitting unbundling may be lower than the current estimation. This is because builders' behaviours will only be reflected in the diffusionperiods' monopolistic profits.

\section{$<$ INSERT TABLE 9 HERE $>$}

\section{Conclusion}

This paper studies regulations that accelerate competition in one market and the effect of these regulations on other related markets that are not targeted by those regulations. In particular, this paper examines the effect of the unbundling of service provision on the structure of competition

\footnotetext{
${ }^{47}$ There is no significant effect of unbundling on regulated firms' profit in the previous section, but Table 9 reports the difference of parameters as if those effects exist.
} 
in infrastructure markets, a focus that has been ignored in the previous literature. It evaluates how usage of the unbundling regulation changes the behaviour of firms that build a natural monopolistic infrastructure, using unique events of fiber-line formation under unbundling regulations.

This study finds that unbundling regulations block new entries and have a monopolization effect on providers of unbundled infrastructure. Using the entry data of cable television firms in building fiber-optic networks, as well as the usage data of regulated fiber-optic facilities, this paper structurally estimates the profit function and the entry sunk cost to identify the regulation effects, assuming a dynamic entry game. Estimation results suggest that regulation reduces the profit of new entrants and prevents them from building their own fiber-optic networks. In the baseline counterfactual simulation, we find that unbundling decreases new entry into infrastructure markets by about $24 \%$.

As a policy implication, this paper suggests the possibility that regulations regarding competition distort market discipline and reduce competition in infrastructure-building markets. New firms build infrastructure, seeking monopolistic profits. Yet if regulations remove the possibility for monopolistic gains, firms will not enter the markets. In the diffusion of new infrastructure, unbundling regulations negatively affect competition in the facilities-building markets. In 1997, when unbundling started globally, government-built metal lines already existed, and privatized companies had been receiving monopolistic profits for a long time. Unbundling opened these networks, and citizens benefited from competition in telecommunications. However, the situation changed in Japan in the 2000s. The regulatory authority unbundled the firms that were building fiber lines, and the resulting system strongly affected their building behaviours. Unbundling decreased entrants' incentives to build new infrastructure. Japan is one of the ironic examples where the regulated carrier has monopolized the fiber-optic facility market, whereas normally unbundling aims to remove the problems of a "natural monopoly."

This prevention of competition in infrastructure markets entails risks. Unbundling may decrease duplicative investment among infrastructure builders. ${ }^{48}$ However, for the next several decades, little infrastructure competition may impede innovation and efficiency of facilities. Whether the benefits of the low unbundling price in the diffusion period outweigh the risks in the long run is still under question, because this market structure may continue in the next decades and efficiency in the information and telecommunications industry is one of the key sources of economic growth nowadays.

Countries all over the world are changing their metallic telephone/CATV lines to fiber-optic

\footnotetext{
${ }^{48}$ Vogelsang (2002) and Hoeffler (2007) claims a trade-off between the advantages of infrastructure-based competition and wasteful duplication.
} 
lines. Policymakers face an important decision as to whether or not they will continue unbundling regulations on the new lines. The United States has chosen to abandon unbundling. Japan continues to enforce the regulation. Our findings from the Japanese experience suggest that unbundling in periods of technological change reduces competition in telecommunication facilities. 


\section{References}

[1] Aguirregabiria, Victor, 2009, "Estimation of Dynamic Discrete Games Using the Nested Pseudo Likelihood Algorithm: Code and Application," Mimeo

[2] Aguirregabiria, Victor, 2012, "A Method for Implementing Counterfactual Experiments in Models with Multiple Equilibria," Economics Letters 114, pp.190-194.

[3] Aguirregabiria, Victor and Chun-Yu Ho, 2012. "A Dynamic Game of Airline Network Competition: Hub-and-Spoke Networks and Entry Deterrence," Journal of Econometrics 168, pp.156-173.

[4] Aguirregabiria, Victor and Pedro Mira 2007, "Sequential estimation of dynamic discrete games." Econometrica 75, 1-53.

[5] Augereau, A., Greenstein, S. and Rysman, M. 2006. "Coordination versus Differentiation in a Standards War: The Adoption of 56K Modems," RAND Journal of Economics 37, pp.887909

[6] Berkman Center 2009 "Next Generation Connectivity: A Review of Broadband Internet Transitions and Policy from Around the World"

[7] Bajari, Patrick, C. Lanier Benkard and Jonathan Levin, 2007. "Estimating Dynamic Models of Imperfect Competition." Econometrica 75, pp. 1331-1370

[8] Bourreau, Marc and Pinar Dogan 2005. "Unbundling the Local Loop," European Economic Review, vol. 49, pp. 173-199.

[9] Bourreau, Marc and Pinar Dogan 2006. "Build or Buy Strategies in Local Markets," American Economic Review, Papers and Proceedings, Vol. 96, no2, pp. 72-76

[10] Bourreau, Marc, Pinar Dogan and Matthieu Manant 2010. "A Critical Review of the "Ladder of Investment" Approach," Telecommunications Policy, Vol. 34(11), pp. 683-696

[11] Bresnahan, T., and P. Reiss 1991. "Entry and competition in concentrated markets," Journal of Political Economy, 99, pp. pp. 977-1009.

[12] Cave, Martin. 2006, "Encouraging infrastructure competition via the ladder of investment," Telecommunications Policy. v30. pp. 223-237

[13] Cave, Martin. 2009, "Snakes and ladders: Unbundling in a next generation world," Telecommunications Policy. v34. pp. 80-85

[14] Chipty, Tasneem. 2001, "Vertical Integration, Market Foreclosure, and Consumer Welfare in the Cable Television Industry," American Economic Review, Vol. 91, No. 3, pp. 428-453.

[15] Chu, Chenghuan Sean, Phillip Leslie, and Alan Sorensen. 2011. "Bundle-Size Pricing as an Approximation to Mixed Bundling," American Economic Review 101 (1): 263-303. 
[16] Collard-Wexler, Allan. 2011, "Demand Fluctuations in the Ready-Mix Concrete Industry," Mimeo

[17] Crandall, Robert W., Ingraham, Allan T. and Singer, Hal J. 2004 "Do Unbundling Policies Discourage CLEC Facilities-Based Investment?" The B.E. Journal of Economic Analysis \& Policy, Vol. 4, pp. 1-23.

[18] Economides, Nicholas, Katja Seim and V. Brian Viard, 2008. "Quantifying the benefits of entry into local phone service," RAND Journal of Economics, vol. 39(3), pages 699-730.

[19] Goldfarb, Avi, and Mo Xiao. 2011. "Who thinks about the competition? Managerial ability and strategic entry in US local telephone markets," American Economic Review 101(7): 31303161

[20] Grajek, Michał and Lars-Hendrik Röller. 2012. "Regulation and Investment in Network Industries: Evidence from European Telecoms," Journal of Law and Economics, Forthcoming

[21] Greenstein, Shane and Mazzeo, Michael. 2006 "The Role of Differentiation Strategy in Local Telecommunication Entry and Market Evolution: 1999-2002," Journal of Industrial Economics, v. 54 , iss. 3 , pp. $323-50$

[22] Ho Katherine, Justin Ho, and Julie Holland Mortimer, 2012. "The Use of Full-Line Forcing Contracts in the Video Rental Industry," American Economic Review 2012, 102(2): 686-719

[23] Höffler, Felix. 2007 "Cost and Benefits from Infrastructure Competition. Estimating Welfare Effects from Broadband Access Competition," Telecommunications Policy, vol. 31, no. 6-7, pp. 401-418.

[24] Hori, Keiichi and Mizuno, Keizo, 2006. "Access pricing and investment with stochastically growing demand," International Journal of Industrial Organization, vol. 24(4), pages 795808 , July.

[25] Jorde T.M., Sidak J.G. and D.J. Teece, 2000. "Innovation, Investment, and Unbundling," Yale Journal on Regulation, vol. 17, pp. 1-37.

[26] Lin, H., 2011, Quality Choice and Market Structure: A Dynamic Analysis of Nursing Home Oligopolies. Mimeo. Indiana University. Business School.

[27] Mazzeo, Michael. 2002. "Product Choice and Oligopoly Market Structure," RAND Journal of Economics. 33(2): 221-242

[28] Pakes, A., Ostrovsky, M., Berry, S., 2007. Simple estimators for the parameters of discrete dynamic games (with entry/exit examples). RAND Journal of Economics 38, 373-399.

[29] Pesendorfer, Martin and Philipp Schmidt-Dengler, 2010. "Sequential Estimation of Dynamic Discrete Games: A Comment," Econometrica, vol. 78(2), pages 833-842

[30] Ryan, Stephen P. 2012. "The Costs of Environmental Regulation in a Concentrated Industry," Econometrica, forthcoming 
[31] Seim, Katja, 2006. "An empirical model of firm entry with endogenous product-type choices," RAND Journal of Economics

[32] Toivanen, O., and M. Waterson. 2005 "Market Structure and Entry: Where's the Beef?," RAND Journal of Economics, 36(3), 680-699.

[33] Vogelsang, Ingo. 2002. "Incentive Regulation and Competition in Public Utility Markets: A 20-Year Perspective," Journal of Regulatory Economics, vol. 22(1), pp. 5-27.

[34] Vogelsang, Ingo and Bridger Mitchell. 1997 "Telecommunications Competition: The Last Ten Miles," MIT Press and AEI Press 
Figure 1: Share of Regulated Firms (NTTs) in Building FTTH Lines
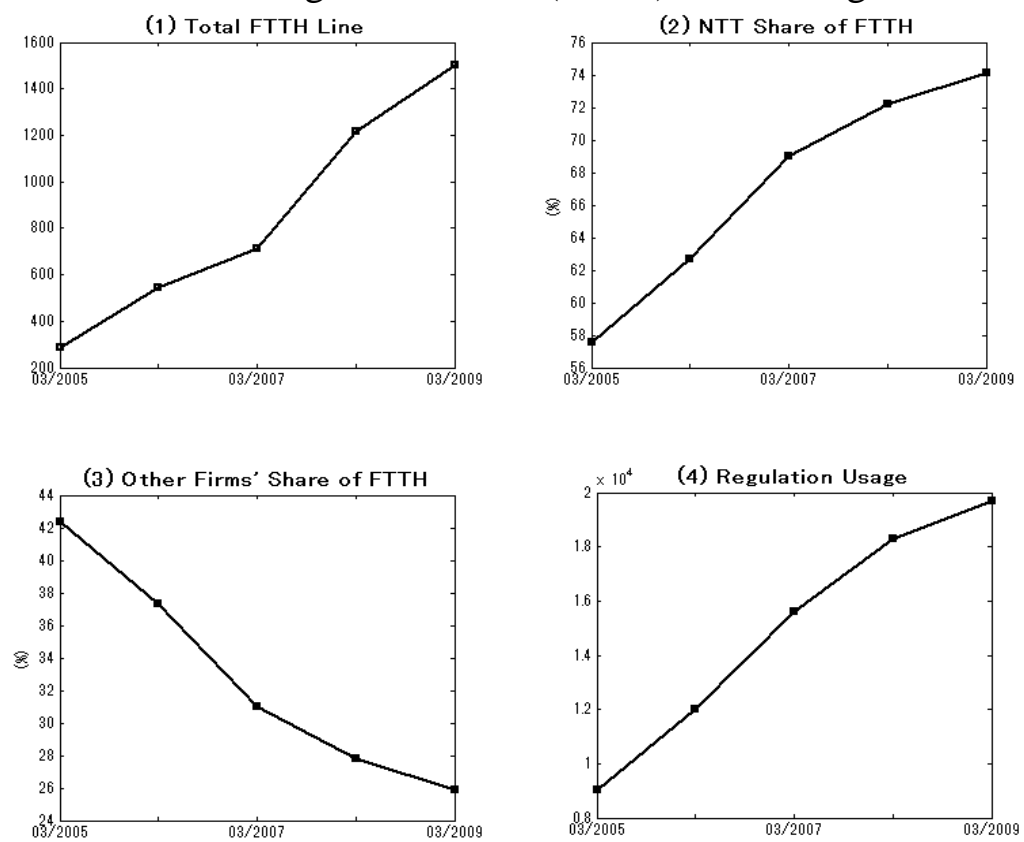

Table 1: Regulations of the Telecommunications Industry in 2009

\begin{tabular}{llllll}
\hline \hline & $\mathrm{US}$ & Japan & Germany & France & $\mathrm{UK}$ \\
\hline 1. Regulation on Wired Lines & & & & & \\
Metallic Line & $\mathrm{R}^{* 1}$ & $\mathrm{R}$ & $\mathrm{R}$ & $\mathrm{R}$ & $\mathrm{R}$ \\
Fiber-optic Line & $\mathrm{U}^{* 2}$ & $\mathrm{R}$ & $\mathrm{U}^{* 3}$ & $\mathrm{U}$ & $\mathrm{U}$ \\
2. Diffusion & & & & & \\
\# of Broadband Subscribers*4 & 81.2 & 30.9 & 24.1 & 18.6 & 17.7 \\
Fiber-optic Share & $6 \%$ & $51 \%$ & $1 \%$ & $0 \%$ & $0 \%$ \\
\hline
\end{tabular}

Top 5 countries by broadband subscribers are shown. Source: OECD

"R" means Regulated, "U" means Unregulated.

*1 US abolished linesharing in 2003, but continues dry copper.

*2 US abolished the regulation on fiber lines in 2003.

*3 Germany abolished the regulation to induce investment in 2005.

*4 The unit is in millions. Data are taken of June 2009. 
Table 2: Fiber Construction and Unbundling Usage

\begin{tabular}{|c|c|c|c|c|c|}
\hline & 2005 & 2006 & 2007 & 2008 & 2009 \\
\hline \multicolumn{6}{|c|}{ (1) \# of CATVs that Build Fiber Networks } \\
\hline 0 per market & 892 & 839 & 828 & 768 & 750 \\
\hline 1 per market & 43 & 89 & 97 & 145 & 160 \\
\hline 2 per market & 0 & 7 & 8 & 18 & 21 \\
\hline 3 per market & 0 & 0 & 0 & 2 & 2 \\
\hline Total & 43 & 103 & 113 & 187 & 208 \\
\hline \multicolumn{6}{|c|}{ (2) \# of Regulated Firms' Fiber Stations } \\
\hline \# of Stations & 3149 & 3302 & 3415 & 3573 & 3644 \\
\hline \multicolumn{6}{|c|}{ (3) \# of Service Providers using Unbundling (FTTH) } \\
\hline \# of Firms & 2831 & 3775 & 4862 & 5644 & 5972 \\
\hline
\end{tabular}

Table 3: Summary Statistics (933 markets, 5 years)

\begin{tabular}{lllll}
\hline \hline & Mean & Std & Min & Max \\
\hline \# of Service Providers using Unbundling (station to home) & 4.95 & 5.26 & 0 & 39 \\
\# of Service Providers using Unbundling (station to station) & 6.30 & 5.71 & 0 & 62 \\
\# of Regulated Firms' Station & 3.66 & 3.22 & 0 & 21 \\
\# of CATVs that Build Fiber Lines & 0.14 & 0.39 & 0 & 3 \\
\# of Households & 25445 & 43433 & 143 & 409193 \\
Area & 224.23 & 259.89 & 3.47 & 1449.87 \\
Income & 2953.03 & 540.27 & 1888.97 & 5884.61 \\
\hline
\end{tabular}

Table 4: Market Characteristics (Mean)

\begin{tabular}{lllll}
\hline \hline $\begin{array}{l}\text { \# of Fiber- } \\
\text { CATV }\end{array}$ & obs. & \multirow{2}{*}{ \# of Households } & $\begin{array}{l}\text { \# of Service Providers } \\
\text { using Unbundling (Home) }\end{array}$ & $\begin{array}{l}\text { \# of Regurated } \\
\text { Firms' Station }\end{array}$ \\
\hline 0 & 4073 & 19,267 & 4.05 & 3.40 \\
1 & 534 & 60,540 & 10.44 & 5.26 \\
2 & 54 & 133,708 & 16.52 & 7.35 \\
3 & 4 & 170,143 & 24.75 & 7.50 \\
\hline
\end{tabular}


Figure 2: Usage Variation of Unbundling in 2008
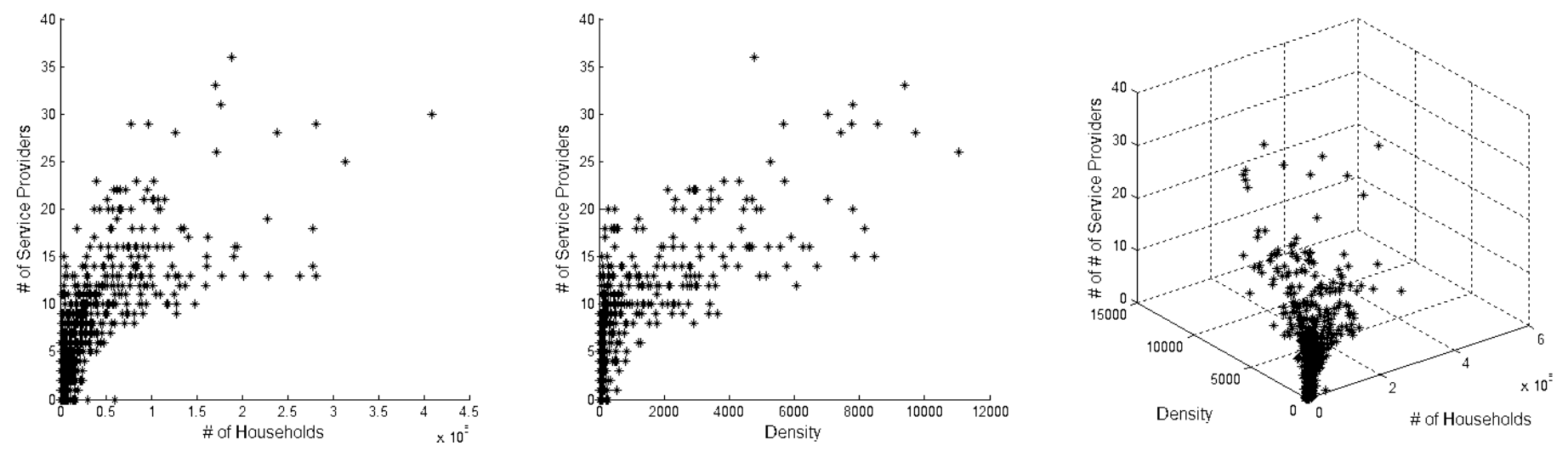

Figure 3: Market Definition: Eastern Japan

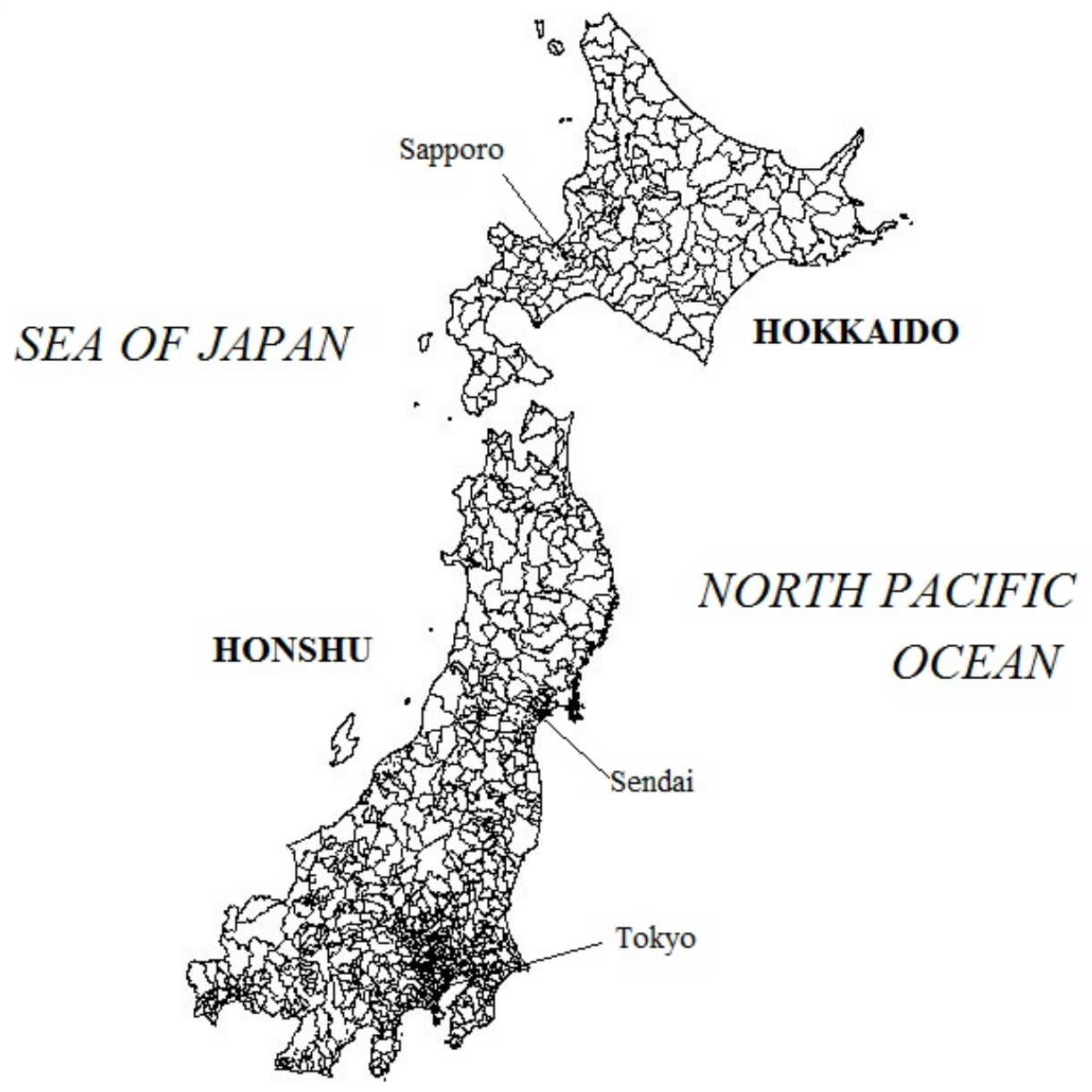


Table 5: Reduced-Form Results of Probit Models

\begin{tabular}{ccc}
\hline \hline & (1) IV Probit & (2) Ordered Probit \\
\hline \multirow{2}{*}{ Dependent Variable } & Unregulated Firms' (CATV') & Regulated Firms' (NTTs') \\
& Entry in FTTH & -0.05 \\
Increase in FTTH Stations
\end{tabular}

Note: * In the IV estimation, this paper uses the logarithm of the number of firms that use the regulated facility between station and station as the instrument of usage for home fiber.

$*$ is significant at $10 \%, * *$ at $5 \%$ and $* * *$ at $1 \%$. Standard deviations are in parentheses. 


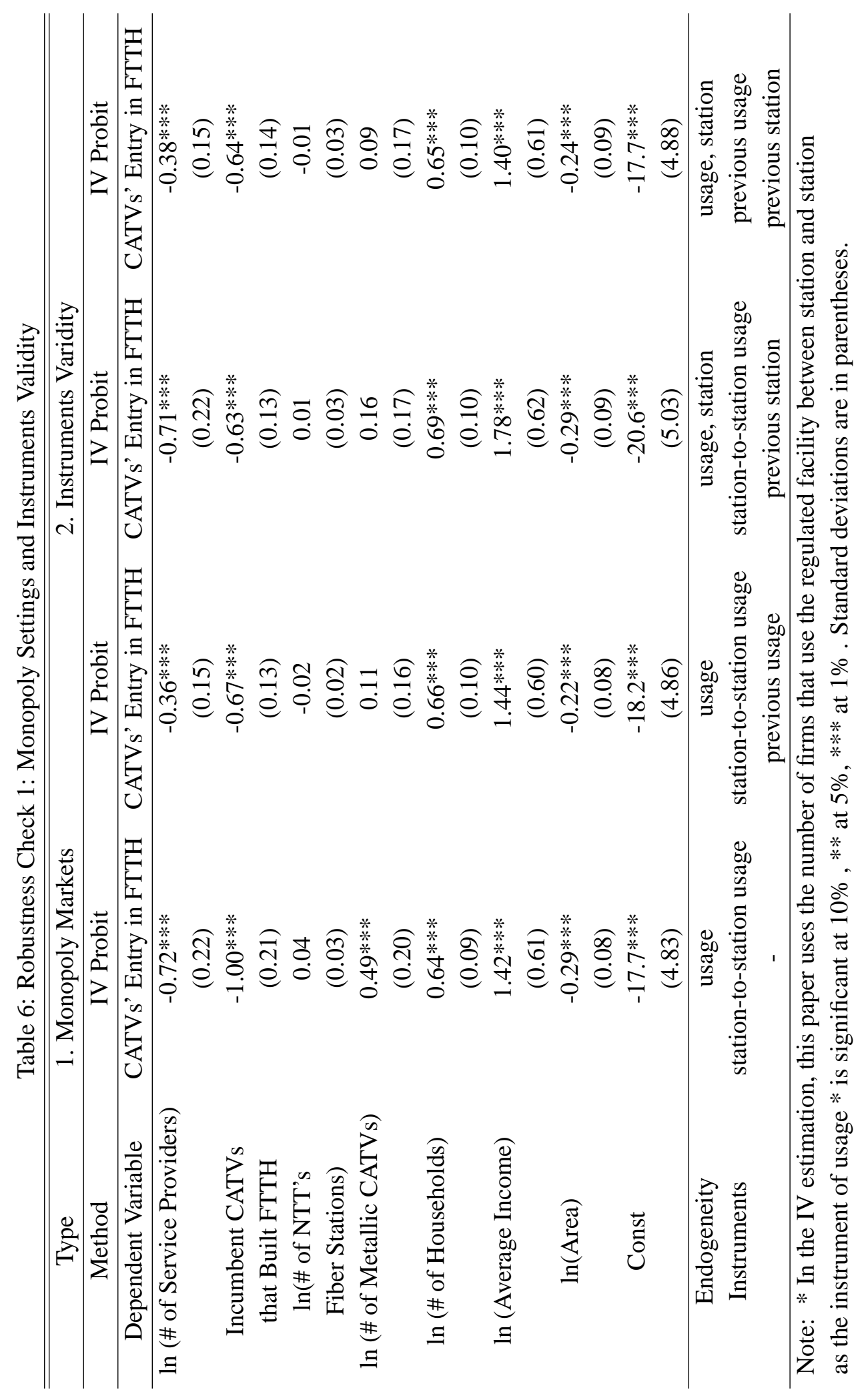


Table 7: Robustness Check 2: Results of Subsample in Urban Areas

\begin{tabular}{ccc}
\hline \hline & (1) IV Probit & (2) Ordered Probit \\
\hline \multirow{2}{*}{ Dependent Variable } & Unregulated Firms' (CATVs') & Regulated Firms' (NTTs') \\
& Entry in FTTH & Increase in FTTH Stations \\
\hline $\ln$ (\# of Service Providers) & $-0.65^{* * *}$ & $0.45^{* * *}$ \\
Incumbent CATVs & $(0.17)$ & $(0.22)$ \\
which Built FTTH & $-0.71^{* * *}$ & -0.32 \\
$\ln$ (\# of NTT's & $(0.13)$ & $(0.26)$ \\
Fiber Stations) & 0.01 & $-0.08^{* *}$ \\
$\ln$ (\# of Metallic CATVs) & $(0.03)$ & $(0.04)$ \\
& $0.54^{* * *}$ & - \\
$\ln$ (\# of Households) & $(0.17)$ & - \\
& $0.65^{* * *}$ & 0.08 \\
$\ln$ (Average Income) & $(0.10)$ & $(0.15)$ \\
& $0.94^{*}$ & -1.21 \\
$\ln$ (Area) & $(0.56)$ & $(1.02)$ \\
& $-0.36^{* * *}$ & $0.45^{* * *}$ \\
Const & $(0.09)$ & $(0.15)$ \\
& $-13.34^{* * *}$ & - \\
Endogeneity & $(4.51)$ & - \\
Year Dummy & $\sqrt{ }$ & - \\
\hline
\end{tabular}

Note: * In the IV estimation, this paper uses the logarithm of the number of firms that use the regulated facility between station and station as the instrument of usage for home fiber.

$*$ is significant at $10 \%, * *$ at $5 \%$ and $* * *$ at $1 \%$. Standard deviations are in parentheses. 


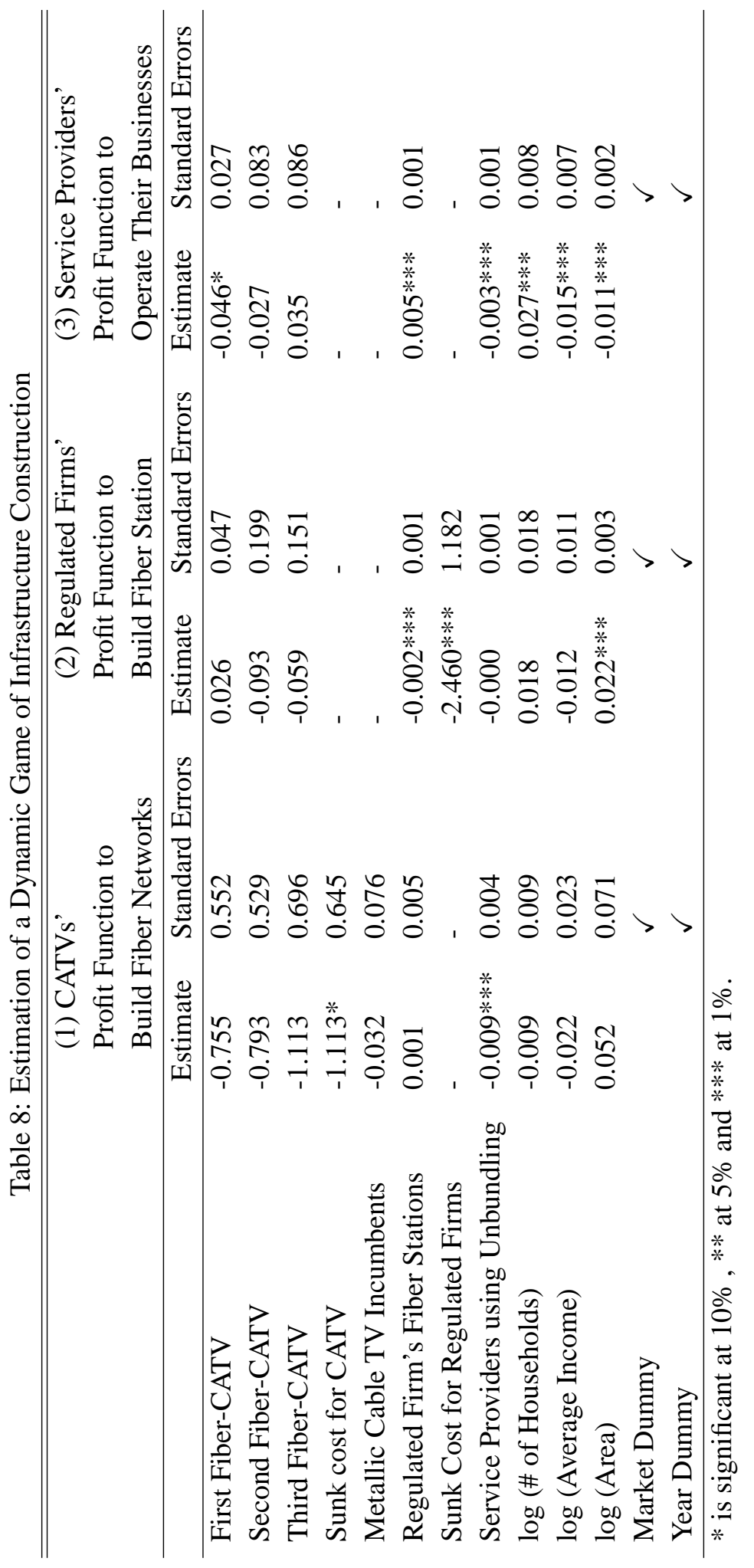


Table 9: Counterfactual Results

\begin{tabular}{|c|c|c|c|c|c|c|c|}
\hline Year & 2005 & 2006 & 2007 & 2008 & 2009 & $\ldots$ & 2015 \\
\hline \multicolumn{8}{|c|}{ (1) \# of CATVs that Build Fiber Lines ${ }^{* 1}$} \\
\hline Data & 43 & 103 & 113 & 187 & 208 & $\ldots$ & - \\
\hline Model Estimates (Unbundling) & 43 & 87.4 & 136.8 & 163.4 & 220.2 & $\ldots$ & 476.0 \\
\hline Counterfactual (No unbundling) & 43 & 102.0 & 174.8 & 212.4 & 291.4 & $\ldots$ & 626.7 \\
\hline Unbundling Effects & - & $-14.31 \%$ & $-21.74 \%$ & $-23.07 \%$ & $-24.43 \%$ & $\ldots$ & $-24.05 \%$ \\
\hline \multicolumn{8}{|c|}{ (2) Regulated Firms' Fiber-Station Construction Level² } \\
\hline Data & 6177 & 6383 & 6528 & 6690 & 6764 & $\ldots$ & - \\
\hline Model Estimates (Unbundling) & 6177 & 6299.2 & 6421.2 & 6539.8 & 6602.3 & $\ldots$ & 6952.8 \\
\hline Counterfactual (No unbundling) & 6177 & 6295.2 & 6412.4 & 6585.2 & 6585.2 & $\ldots$ & 6913.8 \\
\hline Unbundling Effects & - & $+0.06 \%$ & $+0.14 \%$ & $+0.21 \%$ & $+0.26 \%$ & $\ldots$ & $+0.56 \%$ \\
\hline
\end{tabular}

*1 The quantity is measured by the sum of \# of fiber-CATV in a municipality

*2 The quantity is measured by the sum of fiber-station construction level (15 bins) in a municipality 